\title{
Accumulation of technetium in floating aquatic plants
}

\author{
J. Hattink and H.Th. Wolterbeek \\ Interfaculty Reactor Institute, Delft University of Technology, \\ Mekelweg 15, 2629 JB Delft, The Netherlands
}

\begin{abstract}
Technetium $\left({ }^{99} \mathrm{Tc}\right)$ is of radio-ecological and health-physical interest because of its long half-life and its environmental mobility, given it a potential bioavailability. Plants are able to accumulate substantial amounts of Tc. Three mechanisms are suggested to interfere with the Tc accumulation: (i) changes in the plant physiological status, (ii) competitive effects with nutrient uptake, and (iii) electrostatic cell wall interactions. This study focuses on the question whether these mechanisms apply for aquatic plants grown under natural conditions. Tc accumulation in five aquatic plant species correlated strongly with the calcium concentration in the water. Growth rate or possible competition with $\mathrm{Cl}^{-}, \mathrm{NO}_{3}^{-}, \mathrm{PO}_{4}{ }^{3-}$ or $\mathrm{SO}_{4}{ }^{2-}$ did not significantly affect, if affect at all, the Tc accumulation in submerged aquatic plants. This suggests that water hardness is the dominant factor perturbing the Tc accumulation in submerged aquatic plants, supporting the hypothesis that electrostatic cell wall interactions are associated with it.
\end{abstract}

\section{INTRODUCTION}

The present study deals with the possible role of aquatic macrophytes in cycling ${ }^{99} \mathrm{Tc}\left(\beta^{-}\right.$-emitter, half-life $\left.2.1 \times 10^{5} \mathrm{y}\right)$ through aquatic ecosystems. In aquatic systems, ${ }^{99} \mathrm{Tc}$ mainly appears as $\mathrm{TcO}_{4}^{-}$, which doesn't associate with aquatic ligands, given it a high environmental mobility and, consequently, a potential bioavailability. Therefore, ${ }^{99} \mathrm{Tc}$ is of radio-ecological relevance, albeit only moderate radiotoxic [1].

The main question here is which factors perturbing the Tc accumulation in aquatic plants. Three mechanisms are suggested, based on laboratory studies performed under optimal conditions in nutrient rich solutions. First, it may be possible that the plant itself will alter the Tc accumulation because of an altered physiological state. Tc uptake is related to the photosynthetic activity of spinach leaves (Spinacea oleracea) and $L$. minor plants [2,3]. On the other hand, Tc uptake was not related to the growth rate of $L$. minor [4]. The second hypothesis assumes that Tc behaves like an analogue for an essential element. Accumulation of $\mathrm{Tc}$ in terrestrial plants is reduced in fertilized soils [5], which is assigned to the analogy of $\mathrm{TcO}_{4}{ }^{-}$with $\mathrm{NO}_{3}{ }^{-}$in the plants metabolism [6,7], although also $\mathrm{SO}_{4}{ }^{2-}, \mathrm{PO}_{4}{ }^{3-}, \mathrm{SeO}_{4}{ }^{2-}$, or $\mathrm{MoO}_{4}{ }^{2-}$ are reported to inhibit Tc uptake [8]. Recently, it was shown that $\mathrm{NO}_{3}{ }^{-}$also inhibit $\mathrm{Tc}$ accumulation in the submerged grown amphibious aroid Cryptoryna affinis [9]. The last, also physico-chemical based hypothesis states that salinity and hardness perturb Tc uptake. Interactions of cations with the cell wall, altering the overall cell wall potential, would be the driving force. Garnham et al. [10] first suggested this mechanism for marine phytoplankton, which showed enhanced Tc uptake at increasing salinity. Similar effects were observed for Tc accumulation in L. minor in respect to dominant cations in fresh water [11].

The aim of this study was to verify if these mechanisms apply under (semi-) natural conditions. To approach these conditions, plants and water were collected from a ditch and used in ${ }^{95 \mathrm{~m}} \mathrm{Tc}$ uptake studies.

\section{MATERIAL AND METHODS}

${ }^{95 m}$ Tc was obtained from Los Alamos National Laboratory (Los Alamos, NM, USA). The batch also contained a similar activity of ${ }^{97 \mathrm{~m}} \mathrm{Tc}$. Azolla caroliniana Willd., Ceratophyllum demersum L., Spirodela polyrhiza (L.) Schleiden, and Wolffia arrhiza (L.) Horkel, were collected from a ditch nearby the Interfaculty Reactor Institute, Delft, The Netherlands (52 $\left.01^{\prime} \mathrm{N}, 4^{\circ} 21^{\prime} \mathrm{E}\right)$ in August and September 1997. Lemna minor L. was cultured on a $5 \%$ Gorham solution. Plants were kept in plastic tanks $(25 \times 15 \times 15$ 
$\mathrm{cm})$ containing $2 \mathrm{~L}$ of natural water. $C$. demersum plants were placed in separate tanks $(21.5 \times 11 \times 5 \mathrm{~cm})$ with $0.5 \mathrm{~L}$ water. Tanks were placed in a climate room at $23^{\circ} \mathrm{C}$ and $16 \mathrm{~h}$ light per day $\left(150 \mu \mathrm{mol} / \mathrm{m}^{2} / \mathrm{s}\right)$.

Tc was spiked to a concentration of $5 \times 10^{-15} \mathrm{~mol} / \mathrm{L}$. At regular intervals, $0.5 \mathrm{~L}$ water was taken and replaced by fresh solution and plants were sampled. From the water sample, sub-samples were analysed on total $\mathrm{Tc}, \mathrm{TcO}_{4}{ }^{-}, \mathrm{NO}_{3}{ }^{-}, \mathrm{PO}_{4}{ }^{3-}$, and $\mathrm{SO}_{4}{ }^{2-}$. The remaining was weighed, concentrated to $50 \mathrm{~mL}$ using a rotor vapour apparatus and oven dried by $105^{\circ} \mathrm{C}$. The remaining salt was weighed and analysed for $\mathrm{Ca}$, $\mathrm{Mg}, \mathrm{Na}, \mathrm{K}$, and $\mathrm{Cl}$. Plants were sampled by placing plastic rings with a diameter of $3.5 \mathrm{~cm}(L$. minor and $S$. polyrhiza), or fixing a piece of plexiglass between both sides of the tank (A. caroliniana and $W$. arrhiza) just at the water surface. All plants inside these defined areas were taken out, possible with the help of a small fish net. Before starting experiments with $C$. demersum, and direct after sampling, plants were blotted dry and weighed to determine wet weight. Samples were spin-dried to remove attached water, analysed for ${ }^{95 \mathrm{~m}} \mathrm{Tc}$, subsequently dried at $65^{\circ} \mathrm{C}$ overnight and weighed. Experiments were terminated when biomass production was such that not enough plants could be sampled for analysis.

${ }^{95 \mathrm{~m}} \mathrm{Tc}$ was measured within the 162 to $240 \mathrm{keV}$ energy windows using a Wallac gamma counter (Wallac Oy, Turku, Finland). All data were corrected for background and decay and converted into mol Tc, by using the specific activities of both ${ }^{95 \mathrm{~m}, 97 \mathrm{~m}} \mathrm{Tc}$ and the measured activity of an aliquot from the batch. The given activity of ${ }^{95 \mathrm{~m}, 97 \mathrm{~m}} \mathrm{Tc}$ at date of shipment was taken as estimate for the total amount of $\mathrm{Tc}$ present in the batch. $\mathrm{NO}_{3}{ }^{-}, \mathrm{PO}_{4}{ }^{3-}, \mathrm{SO}_{4}{ }^{2-}$ were measured by standard methods using a Cobas Mira autoanalyser (Hoffmann-La Roche Ltd, Basel, Switzerland). $\mathrm{Ca}, \mathrm{Mg}, \mathrm{Na}, \mathrm{K}, \mathrm{Cl}$ were determined by multi element instrumental neutron activation analysis (Interfaculty Reactor Institute, Delft, The Netherlands).

Tc uptake in water plants was quantified by using the Tc accumulation model for $L$. minor [12]. This model expresses the $\mathrm{Tc}$ concentration in the plant, $[\mathrm{Tc}]_{\text {plant }}(\mathrm{t})$ as function of the exponential growth rate, $\mathrm{k}_{\mathrm{g}}$, an overall accumulation rate constant, $\mathrm{K}_{\mathrm{acc}}$, comprising all possible uptake and elimination processes, and the $T c$ concentration in the water, $[\mathrm{Tc}]_{\text {water }}$. However, the equations given in ref. [12] require that both $\mathrm{k}_{\mathrm{g}}$ and $[\mathrm{Tc}]_{\text {water }}$ are constant, which was not the case in the present work. Instead, we assumed that the change of $k_{g}$ and $[\mathrm{Tc}]_{\text {water }}$ between two measurements, at $t=t_{i-1}$ and $t=t_{i}$ was small and the average was taken as estimate for the time interval. The accumulation in this interval is then described by:

$$
[T c]_{\text {plant }}\left(t_{i}\right)=\frac{K_{a c c}}{k_{g}}[T c]_{\text {water }} \times\left(1-e^{-k_{g} \times\left(t_{i}-t_{i-1}\right)}\right)+[T c]_{\text {plant }, t_{i-1}} \times e^{-k_{g} \times\left(t_{i}-t_{i-1}\right)}
$$

The first part describes the accumulation of Tc during the interval $t_{i-1}$ and $t_{i}$, the second part accounts for dilution of $\mathrm{Tc}$ that was already taken up before $\mathrm{t}_{\mathrm{i}-1}$ by new biomass. From Eq. [1] accumulation rate constants $\left(\mathrm{K}_{\mathrm{acc}}\right)$ were calculated and plotted against relative growth rates, solution dry rest, $\mathrm{Ca}^{2+}, \mathrm{Cl}^{-}$, $\mathrm{NO}_{3}{ }^{-}, \mathrm{PO}_{4}{ }^{3-}$ and $\mathrm{SO}_{4}{ }^{2-}$ concentrations. Relations were linear, and correlation coefficients $(r)$ are reported.

\section{RESULTS}

\subsection{Accumulation of $\mathrm{Tc}$ in aquatic plants}

Tc mass balances were complete and showed that Tc was distributed over biomass and water. Tc remains $\mathrm{TcO}_{4}{ }^{-}$in the water as determined by a tetraphenyl-arsoniumchloride extraction. Tc accumulated in the plants, but no steady state was reached within the experiment (Fig. 1). The highest accumulation was found in $S$. polyrhiza; almost all Tc initially present in the water was taken up. A. caroliniana, L. minor, and $W$. arrhiza accumulated continuously $\mathrm{Tc}$, but depletion of Tc from water did not occur. $C$. demersum seems to reach a steady state, but the Tc concentration in the water increased, due to evaporation.

Biomass increased 1.5 ( C. demersum) to 127 (S. polyrhiza) times the initial amount. Growth rates of Lemnaceae decreased (Fig. 2), and were correlated with the phosphate concentration $(r=0.97)$. Growth rates for $C$. demersum and A. caroliniana were independent of time and nutrient concentration, but here nutrients were not depleted. Obviously, from these data no clear picture can be made regarding processes perturbing $T c$ accumulation in aquatic plants. Possible dilution by new biomass, possible altered accumulation rates by a changed physiological state, competition with anion uptake or electrostatic effects may all be present. 

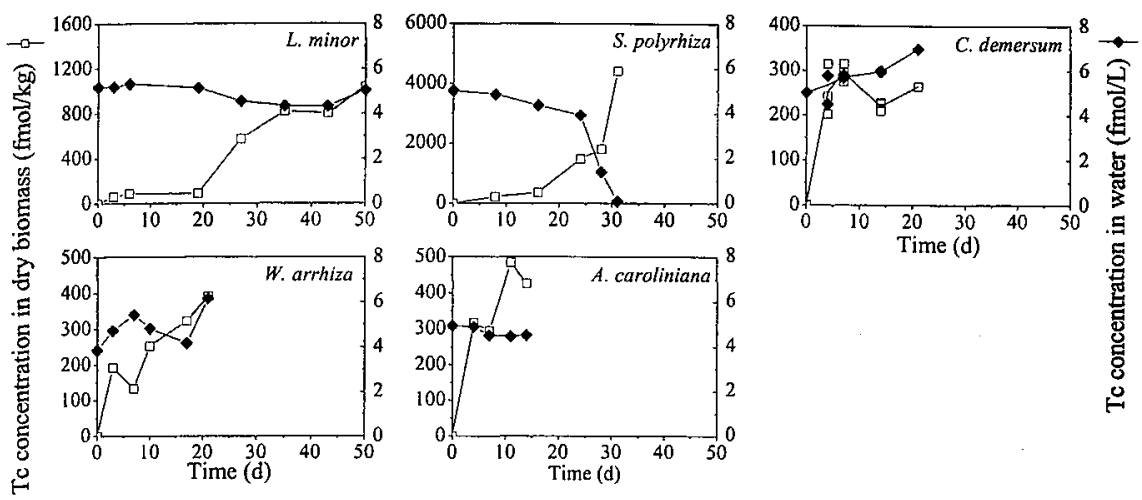

Figure 1. Tc accumulation in aquatic plants from water. Open squares ( $\square$ ) present total Tc concentration in plant biomass and should be read on the left axis. Black squares $(\bullet)$ present $\mathrm{TcO}_{4}^{-}$concentration in water and should be read on the right axis.

Therefore, accumulation rate constants were calculated (Eq. [1], Fig. 2). These rate constants may be a function of growth rate (i.e. physiological dependence) or physico-chemical factors, e.g. anion concentration (competition effects) or water hardness (electrostatic effects). Accumulation rate constants for $L$. minor decreased until day 20 , then "jumps" to $15 \mathrm{~L} / \mathrm{kg} / \mathrm{d}$ only to decrease again afterwards. Accumulation rate constants for $S$. polyrhiza and $C$. demersum decreased in time. Accumulation rate constants for $W$. arrhiza are scattered around $11 \mathrm{~L} / \mathrm{kg} / \mathrm{d}$, while for $A$. caroliniana they tend to be inversely related with growth rate. A slight significant difference could be detected between individual average accumulation rate constants, $\mathrm{K}_{\mathrm{acc}}(\mathrm{F}$-test, $\alpha=0.05, \mathrm{P}=0.05)$. This could be ascribed to differences between C. demersum and $S$. polyrhiza $\left(\mathrm{K}_{\mathrm{acc}}\right.$ of $7 \pm 4$ vs. $13 \pm 5 \mathrm{~L} / \mathrm{kg} / \mathrm{d}$; t-test, $\left.\alpha=0.05, \mathrm{P}=0.02\right)$ and between $C$. demersum and $W$. arrhiza ( $\mathrm{K}_{\text {acc }}$ of $7 \pm 4$ vs. $14 \pm 8 \mathrm{~L} / \mathrm{kg} / \mathrm{d}$; $\mathrm{t}$-test, $\alpha=0.05, \mathrm{P}=0.03$ ).
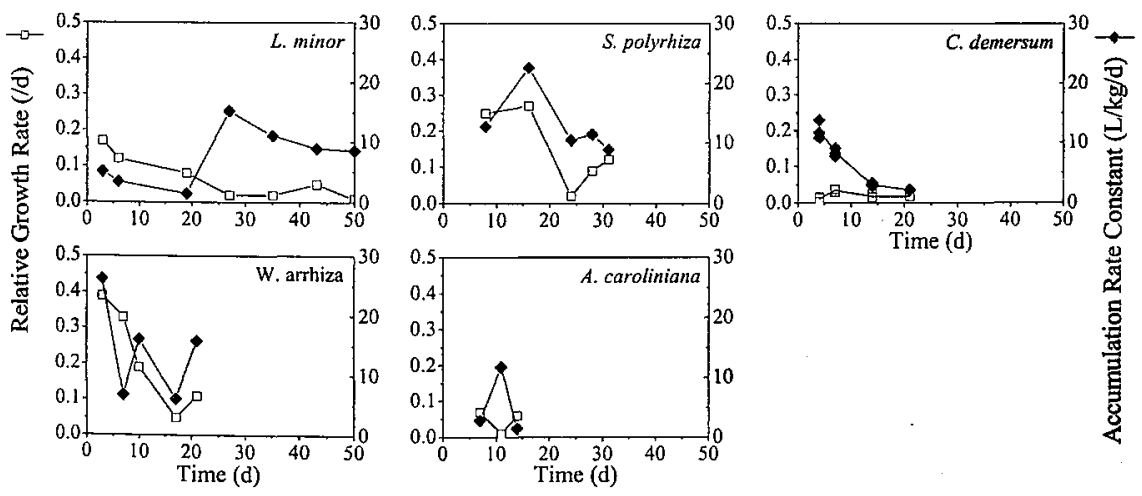

Figure 2. Relative growth rates ( $\square$, left axis) and accumulation rate constants on a dry wt for $\mathrm{Tc}(\diamond$, right axis).

\subsection{Physiological and physico-chemical interactions with the Tc accumulation}

If the plant itself alters the Tc accumulation, it is likely that the Tc accumulation rate constant will be a function of growth rate (as plant physiological status). However, the data did not show such a relation $(r=$ +0.11 , Table 1); although correlations vary for the individual species.

The physico-chemical interaction hypothesises predict a trend of Tc accumulation with the dry rest of the solution. After all, the dry rest represents both cation and anion concentrations. Depending on the 
possible process a negative (competition between nutrients and Tc uptake) or positive trend (electrostatic cell wall interactions) should be obtained. Table 1 shows a positive correlation between Tc accumulation rate constants and dry rests (expect for $A$. caroliniana), suggesting that cations interfere with Tc uptake. No correlation with $\mathrm{NO}_{3}{ }^{-}, \mathrm{PO}_{4}{ }^{3-}, \mathrm{SO}_{4}{ }^{2-}$, or $\mathrm{Cl}^{-}$was observed, although individual responses varied.

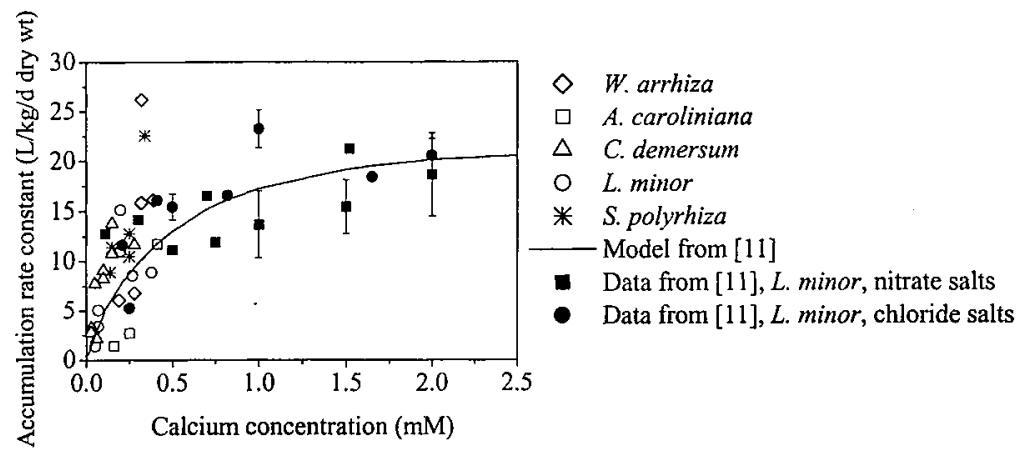

Figure 3. Accumulation rate constants for several aquatic plants as function of the calcium concentration in the solution.

Calcium may strongly interact with the Tc accumulation in aquatic plants, as shown for $L$. minor [11]. In the present study, correlations coefficients turned out to be positive and correlations were higher than for the total salt concentrations $(+0.77$ versus +0.43 , Table 1$)$. This correlation between accumulation rate constant and calcium concentration was the highest correlation found among the factors tested and most consistent between the individual plant species (all positively correlated, $r \geq 0.60$ ). Fig. 3 plots the accumulation rate constants as function of the calcium concentration, including some data and the model from Hattink and Wolterbeek [11]. Interestingly, accumulation rate constants for other species than $L$. minor also seem to match the model predictions (Fig. 3). The present data tend to be slightly higher than, but deviate not significant from the model (t-test, $\alpha=0.05, \mathrm{P}=0.09$ ). However, the model may indeed predict higher accumulation rate constants. The model, as it is, extrapolates the accumulation rate constants as were the plants grown on a Gorham nutrient solution, containing besides $\mathrm{Ca}^{2+}$, also $\mathrm{Mg}^{2+}$ and $\mathrm{K}^{+}$. The actual solutions contained, apart from $\mathrm{Ca}^{2+}, \mathrm{Mg}^{2+}$ and $\mathrm{K}^{+}$, also $\mathrm{Na}^{+}\left(2 \times 10^{-3} \mathrm{~mol} / \mathrm{L}\right) . \mathrm{Na}^{+}$is also responsible for some screening of charges in the cell wall and its presence results in a slightly higher screening compared to a Gorham nutrient solution containing similar, low calcium concentrations. In turn, higher accumulation rate constants result. This effect will fade out at higher calcium concentrations.

Table 1. Correlation coefficients $(r)$ between accumulation rate constants and relative growth rate (RGR), medium concentration of total salt (Dry rest), calcium $\left(\mathrm{Ca}^{2+}\right)$, nitrate $\left(\mathrm{NO}_{3}{ }^{-}\right)$, phosphate $\left(\mathrm{PO}_{4}{ }^{3-}\right)$, sulphate $\left(\mathrm{SO}_{4}{ }^{2-}\right)$, and chloride $\left(\mathrm{Cl}^{-}\right)$.

\begin{tabular}{llllllll}
\hline & $\mathrm{RGR}$ & Dry rest & $\mathrm{Ca}^{2+}$ & $\mathrm{NO}_{3}{ }^{-}$ & $\mathrm{PO}_{4}{ }^{3-}$ & $\mathrm{SO}_{4}{ }^{2-}$ & $\mathrm{Cl}^{-}$ \\
\hline A. caroliniana & -0.97 & -0.14 & +0.97 & 0.00 & +0.42 & +0.10 & -0.30 \\
C. demersum & -0.09 & +0.59 & +0.82 & +0.67 & -0.75 & -0.27 & -0.48 \\
L. minor & -0.68 & +0.85 & +0.60 & -0.63 & -0.56 & +0.57 & +0.10 \\
S. polyrhiza & +0.71 & +0.41 & +0.84 & 0.00 & +0.73 & +0.16 & +0.71 \\
W. arrhiza & +0.50 & +0.44 & +0.61 & -0.28 & +0.41 & +0.07 & +0.46 \\
\hline Average & -0.11 & +0.43 & +0.77 & -0.05 & +0.10 & +0.13 & +0.10 \\
\hline
\end{tabular}

\section{DISCUSSION}

\subsection{Physico-chemical vs. physiological interference}

The present results show that aquatic plants are able to accumulate $\mathrm{TcO}_{4}{ }^{-}$from water. $\mathrm{Tc}$ concentrations in the plant biomass didn't reach a stable concentration. In general, accumulation rate constants did not show a unifying correlation with the growth rate, but tend to be positively correlated with the total salt 
concentration in the solution. Correlations of the accumulation rate constants with several anions were obscure and not negatively correlated, as would be expected in case of competitive effects. In contrast, the accumulation rate constants were positively correlated with the calcium concentrations in the solution, which tend to support the role of electrostatic interactions in the cell wall $[10,12]$. However, based on these data solely, possible physiological or competitive effects cannot be ruled out.

Lembrechts and Desmet [2] showed that the Tc accumulation rate was related to the photosynthetic activity of the leaves. In the present study, light intensity was kept constant, but possible differences between the individual species might be related to differences in photosynthetic efficiency between plant species. If this mechanism should be dominant, rather than electrostatic effects, questions can be placed by the fact that Tc accumulation rate constants for $C$. demersum does not differ from $L$. minor and $A$. caroliniana and that the accumulation rate constants for the other species do not differ at all.

The statistical independence between growth rates and accumulation rate constants is supported by experimental studies with $L$. minor. Hattink et al. $[4,12]$ found no effects of the growth rate of $L$. minor on the accumulation rate constants of Tc. In contrast, Maskin and Shikov [9] suggested that fast growing aquatic plants exhibited higher accumulation rates than slow growing aquatic plants. However, Maskin and Shikov based their conclusions on the overall growth rates as qualitatively observed in an aquarium. They did not report the actual growth rates under the experimental conditions (Tc concentrations of $0.2 \times$ $10^{-3} \mathrm{~mol} / \mathrm{L}$ ), but observed that fast growing plants died during the experiment.

\subsection{The Tc analogue concept}

$\mathrm{TCO}_{4}{ }^{-}$may act like a nutrient anion in its uptake behaviour. Krijger et al. [7] argued that interaction of anions and $\mathrm{TcO}_{4}^{-}$accumulation should be assigned to competitive membrane transport of anions and $\mathrm{TcO}_{4}^{-}$. The present results don't support any competitive effects, but these may still exist in aquatic plants, although these are apparently over-shaded by the effect of cations. Major constituents of the solutions were chloride and sulphate salts. Both anions did not effect the Tc accumulation in L. minor [3] and spinach [6] (see also Fig. 3). We also did not found any interactions between $\mathrm{NO}_{3}{ }^{-}$or $\mathrm{PO}_{4}{ }^{3-}$ in Tc accumulation in L. minor cultivated in nutrient rich solutions [3]. On the other hand, Tc accumulation in submerged grown $C$. affinis was inhibited by high sodium nitrate concentrations $(0.2$ to $1.0 \mathrm{~mol} / \mathrm{L})$ [9].

Alternatively, Tc might substitute an essential element. If Tc would follow an essential element, it should reach a certain concentration proportional to the element concentration in the plant biomass [12]. In the present study Tc concentrations are very low and biomass production was such that it can be assumed that the biomass present is formed from the nutrients, and their possible (Tc) analogue, in the solution. This is in particular true for L. minor, S. polyrhiza, and W. arrhiza, showing a biomass increase of 13,127 , and 20 times their initial amount, respectively. The concentration of essential elements (N, $P$, $\mathrm{K}, \mathrm{Ca}, \mathrm{Mg}, \mathrm{Zn}, \mathrm{Mo}, \mathrm{Fe}$, and $\mathrm{Mn}$ ) in the plant material was indeed constant and did not show any correlation with time or growth rate (data not shown). However, the Tc concentration increased continuously (Fig. 1). Thus, it is not likely that Tc replace any essential element in the plant biomass. Studies on the biotransformation of $\mathrm{Tc}$ showed that $\mathrm{Tc}^{\mathrm{VII}}$ is reduced to $\mathrm{Tc}^{\mathrm{V}}$ by the photosytem and subsequently bound to cysteine, glutathione, and proteins [2,13,14]. Harms et al. [13] and Krijger et al. [14] showed conclusively that these Tc-forms are actually complexes and that Tc does not substitute any element, like $\mathrm{S}$ or $\mathrm{N}$, in these molecules.

\subsection{Diffusion through the unstirred water layer vs. membrane transport of $\mathrm{TcO}_{4}^{-}$}

An interesting and curious point is the closeness of accumulation rate constants between the plant species (Fig. 3). The accumulation rate constant characterises several processes including diffusion through the unstirred water layer around the plant, diffusion through the cell wall, transport of $\mathrm{TcO}_{4}{ }^{-}$across the biomembranes, release of $\mathrm{TCO}_{4}^{-}$, and reduction and complexation of Tc. It sounds reasonable to explain the closeness of the accumulation rate constants by the limited rate of the diffusive flux of $\mathrm{TcO}_{4}^{-}$over the unstirred water layer surrounding the plant, considering the low concentration of Tc $\left(5 \times 10^{-15} \mathrm{~mol} / \mathrm{L}\right)$. Although not very obvious from the present data, the accumulation rate constants for $L$. minor (obtained at $5 \times 10^{-15} \mathrm{~mol} / \mathrm{L} \mathrm{Tc}$ ) seems to fit into the data from Hattink and Wolterbeek [11] for L. minor obtained 
at $5 \times 10^{-7} \mathrm{~mol} / \mathrm{L}$ Tc. Other studies $[3,12]$ showed that the accumulation rate constant was indeed constant up to $10^{-5} \mathrm{~mol} / \mathrm{L}$. Thus the accumulation rate of Tc in aquatic plants may be limited by the diffusion rate over the unstirred water-layer around the plant, just as, for example the $\mathrm{HCO}_{3}{ }^{-}$uptake.

Diffusion is related to the accumulation rate via the surface to weight ratio of the plant. The surface to weight ratio is not equal for all species. $W$. arrhiza may be considered as spherical, having the lowest surface to weight ratio, while $C$. demersum, with its poly-branched leaves, will have the highest surface to weight ratio. A. caroliniana, L. minor, and S. polyrhiza are in general round to elliptical shaped, and will have surface to weight ratios in between. Thus, in turn, would diffusion through the unstirred water layer be the driving force, systematic higher accumulation rate constants should be obtained for $C$. demersum, while $W$. arrhiza should have the lowest accumulation rate constants. However, the data (Fig. 2) do not show such systematic differences between species, thus questions the explanation of diffusion.

\subsection{Root uptake vs. foliar absorption}

The present work focussed on aquatic plants using foliar absorption for their nutrient requirements However, many aquatic plants, such as helophytes, using their roots to take up their nutrients, just as terrestrial plants do. Accumulation rate constants for Tc in terrestrial plant leaves range from $26 \pm 2$ to $320 \pm 180 \mathrm{~L} / \mathrm{kg} / \mathrm{d}$ dry wt $[6,14]$, a factor 10 to 100 higher than reported here for aquatic plants. To tes whether this difference may lie in a different uptake pathway, we performed an additional accumulation experiment with Pistia stratiotes L, a floating plant that shows, instead of leaf absorption, a root uptake pathway for its nutrients. We calculated an accumulation rate constant of $434 \pm 121 \mathrm{~L} / \mathrm{kg} / \mathrm{d}$ dry wt for its leafs. This value is more close to accumulation rate constants for terrestrial plants. Apparently, foliag absorption of $\mathrm{TcO}_{4}^{-}$is less effective than root uptake. Whether these differences also lead to a different $\mathrm{Tc}$ accumulation behaviour in respect to competitive effects or cell wall interactions is still unknown.

\section{CONCLUSIONS}

The main question in this study was which processes, physiological or physico-chemical, perturbate the accumulation of Tc in aquatic plants under natural conditions. The present results suggest that water hardness is the main factor perturbing the Tc accumulation in submerged aquatic plants. Interactions of calcium ions with negative charges in the cell wall may explain this behaviour. In hard waters, relative more charges in the cell wall are bound, resulting in higher $\mathrm{TcO}_{4}{ }^{-}$concentrations in the cell wall, and in turn, a higher Tc uptake. The physiological state of the plant or competition between nutrient anions and Tc uptake do not significantly affect, if affect at all, the Tc accumulation in submerged plants.

\section{References}

[1] Lieser K.H., Radiochim. Acta 63 (1993) 5-8.

[2] Lembrechts J.F. and Desmet G., Health Physics 57 (1989) 255-262.

[3] Hattink J., De Goeij J.J.M., Wolterbeek H.Th., Environ. Exp. Bot. 44 (2000) 9-22.

[4] Hattink J., De Goeij J.J.M., Wolterbeek H.Th., J. Radioanal. Nucl. Chem. 249 (2001) 221-225.

[5] Echevarria G., Vong P.C., Morel J.L., J. Environ. Radioact. 38 (1998) 163-171.

[6] Van Loon L., Doctorate Thesis, Kinetic aspects of the soil-to-plant transfer of technetium. Catholic University Louvain, Louvain, 1986.

[7] Krijger G. C., Kollöffel C., Wolterbeek H.Th., J. Environ. Qual. 29 (2000) 866-870.

[8] Cataldo D.A., Wildung R.E., Garland T.R., Plant Physiol. 73 (1983) 849-852.

[9] Maskin A.N., Shikov S.L., Radiochem. 42 (2000) 288-291.

[10] Garnham G.W., Codd G.A., Gadd G.M., Appl. Microbiol. Biotechnol. 37 (1992) 679-684.

[11] Hattink J., Wolterbeek H.Th., Eniviron. Tox. Chem. 20 (2001) 996-1002.

[12] Hattink J., Wolterbeek H.Th., J. Environ. Rad. 57 (2001) 117-138.

[13] Harms A.V., Krijger G.C., Van Elteren J.T., De Goeij J.J.M, J. Environ. Qual. 28 (1999) 1188-1194.

[14] Krijger G.C, Harms A.V, Leen R, Verburg T.G, Wolterbeek B, Environ. Exp. Bot. 42 (1999) 69-81. 